\title{
Study of the Carbonization and Graphitization of Coal Tar Pitch Modified with SiC Nanoparticles
}

\author{
Maciej Gubernat, ${ }^{1}$ Tomasz Lis, ${ }^{1}$ Janusz Tomala, ${ }^{2}$ Jakub Kawala, ${ }^{2}$ Aneta Fraczek-Szczypta, \\ and Stanislaw Blazewicz ${ }^{1}$ \\ ${ }^{1}$ Faculty of Materials Science and Ceramics, AGH University of Science and Technology, Al. Mickiewicza 30, 30-059 Cracow, Poland \\ ${ }^{2}$ SGL Carbon Polska S.A., ul. Piastowska 29, 47-400 Raciborz, Poland \\ Correspondence should be addressed to Stanislaw Blazewicz; blazew@agh.edu.pl
}

Received 19 December 2016; Revised 1 March 2017; Accepted 12 March 2017; Published 23 March 2017

Academic Editor: Yasuhiko Hayashi

Copyright (C) 2017 Maciej Gubernat et al. This is an open access article distributed under the Creative Commons Attribution License, which permits unrestricted use, distribution, and reproduction in any medium, provided the original work is properly cited.

\begin{abstract}
Silicon carbide nanoparticles (nSiC) have been used to modify coal tar pitch (CTP) as a carbon binder. The influence of ceramic nanoparticles on the structure and microstructure was studied. The structure of CTP-based carbon residue with various nSiC contents was analyzed by using SEM with EDAX, Raman spectroscopy, and X-ray diffraction. The effect of ceramic nanofiller on the crystallite sizes $\left(L_{c}, L_{a}\right)$ and the $c$-axis spacing $\left(d_{002}\right)$ in carbonized samples after heating from 1000 to $2800^{\circ} \mathrm{C}$ was analyzed. Ceramic nanofillers inhibit structural changes in carbonized samples heated to $1000^{\circ} \mathrm{C}$. After heating CTP with nSiC above $2000^{\circ} \mathrm{C}$, the carbon samples contained two carbon components differing in structural ordering. Ceramic nanoparticles increase carbon crystallite growth, while their impact on the $c$-axis spacing is low.
\end{abstract}

\section{Introduction}

Coal tar pitches (CTPs) are the most important binders used in the synthetic graphite industry due to their ability to form pure carbon residues in high yield, together with good adhesive properties after carbonization and graphitization [1]. Graphitized materials display the high electrical conductivity needed to produce electrodes for metal processing and anodes and cathodes for aluminium oxide electrolysis. Physical and mechanical properties of graphitic carbons make them unique materials for working under extreme conditions, that is, elevated temperature, corrosive ambient conditions, and thermal stresses [2]. These properties are directly related to the microstructure and the structure of carbon materials, which, in turn, are formed during hightemperature treatment. During the early stage of annealing to about $1000^{\circ} \mathrm{C}$, chaotically oriented structural units (graphene layers) are formed and further high-temperature treatment is required to convert them into graphitic structure. Such structural changes lead to a decreasing band gap between the valence and conduction bands and to improvement of the electrical conductivity of the carbon [3].
At present, emphasis is focused on the development of carbon-based technologies involving improved methods of processing from raw materials to end products, taking into account new environmental regulations and energy efficiency aspects. In particular, energy consumption is considered when producing some graphite products, requiring temperatures close to $3000^{\circ} \mathrm{C}$. Thus, improved energy efficiency for the manufacture of graphite products by optimization of the graphitization process seems to be a challenge for this industry.

The study presents one of the possible ways to manufacture carbon electrode products at lower processing temperatures.

Silicon carbide is known as a filler that can improve the oxidation resistance of carbon materials [4-7]. This component has already found application in $\mathrm{C} / \mathrm{C}$ composites [8-10]. $\mathrm{SiC}$ in various nanometric forms can also enhance the mechanical properties of synthetic carbons [11-15].

Nano-Si-derived additives including $\mathrm{nSiC}$ can act as graphitization catalysts [16-18]. Conversion of silicon component into carbide phase in the presence of CTP-based carbon may occur already at $1300^{\circ} \mathrm{C}[19,20]$. The presence of $\mathrm{SiC}$ phase in 
carbon matrix may lead to a change in the mechanism of the graphitization process. This ability seems to be a promising way of enhancing the structural and microstructural changes of graphitized materials and optimizing high-temperature processing to manufacture them at lower graphitization temperatures.

The objective of the study was to determine the influence of $\mathrm{nSiC}$ particles on CTP conversion into carbon and graphitic phases.

\section{Materials and Methods}

CTP with softening point $103^{\circ} \mathrm{C}$ was modified with nSiC, 45-55 $\mathrm{nm}$ particle size from NanoAmor.

First, $\mathrm{nSiC}$ filler was deagglomerated in ethanol suspensions by a sonication process. DLS analysis of the as-received powder showed that it consisted of grain fractions in the range from about 750 to $1200 \mathrm{~nm}$, and, after the sonication process, the powder consisted of grain fractions ranging from 80 to $1050 \mathrm{~nm}$. The DLS spectrum of the sonicated powder additionally contains a band corresponding to the presence of small amounts of larger aggregated grains having an average size of about $1450 \mathrm{~nm}$.

After that process, the suspensions containing the determined amounts of the ceramic filler and CTP powder were mechanically mixed for 5 minutes at room temperature. To evaporate ethanol from the mixture, the suspensions were dried at $70^{\circ} \mathrm{C}$ for 24 hours. Finally, the compositions were heated to $165^{\circ} \mathrm{C}$ to transform CTP into liquid state and mechanically stirred for 15 minutes. The detailed procedure of $\mathrm{nSiC}$ deagglomeration and homogenization with CTP is described elsewhere [21]. According to this procedure, CTP samples containing different amounts of $\mathrm{nSiC}$ from $2 \%$ to $10 \%$ were prepared. The samples were then heat-treated at 1000,2000 , and $2800^{\circ} \mathrm{C}$. Annealing to $1000^{\circ} \mathrm{C}$ was carried out in a furnace under argon flow at $90 \mathrm{l} / \mathrm{h}$ with a heating rate of $2^{\circ} \mathrm{C} / \mathrm{min}$. Heat treatment at higher temperatures was carried out in an Acheson furnace. The microstructural and structural changes occurring in CTP-based carbon binder precursors containing various amounts of $\mathrm{nSiC}$ during heat treatment to $2800^{\circ} \mathrm{C}$ were studied. Samples were analyzed by Scanning Electron Microscopy with Energy Dispersive Spectroscopy Analyzer (SEM + EDS) using a Nova NanoSEM 200 microscope connected to an EDAX EDS point analyzer. $\mathrm{X}$-ray diffraction (XRD) was carried out using an X'Pert Pro from Philips, and Raman spectroscopy was carried out using a Horiba LabRAM HR spectrometer connected to a camera with a laser whose excitation wavelength was $532 \mathrm{~nm}$. The results of XRD and Raman spectroscopy were analyzed using Fityk software version 0.9.8. Deconvolution of the complex peaks was carried out using the Pseudo-Voigt function.

\section{Results and Discussion}

The microstructure of the CTP-based carbons modified with $\mathrm{nSiC}$ was studied by SEM + EDS. EDS analysis of carbon samples with $\mathrm{nSiC}$ contents of $2 \%$ (Figure 1) and above shows silicon element as an indicator of the presence of $\mathrm{SiC}$. SEM and EDS studies indicated that SiC nanoparticles

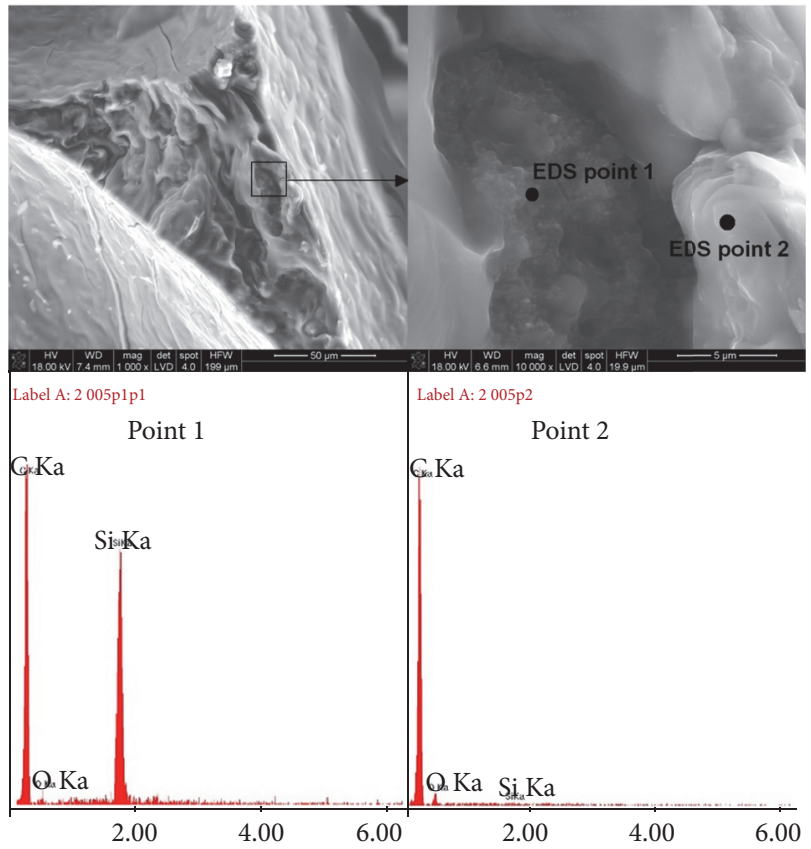

FIGURE 1: CTP-based carbon materials with $2 \% \mathrm{nSiC}$ contents after heat treatment at $1000^{\circ} \mathrm{C}$.

were found in the carbon matrix in the form of clusters of micrometre size. Such clusters were separated from each other by areas with slightly lower $\mathrm{nSiC}$ content (Figure 1). The presence of such ceramic clusters was characteristic for all the modified carbon samples, independently of the content of the ceramic filler, and they were formed as a result of secondary agglomeration of the nanoparticles after homogenization in liquid CTP and the initial stage of carbonization. The presence of the carbide phase with different grain sizes in liquid CTP can cause differential conversion of CTP into carbon, resulting in the formation of carbon crystallites that differ in size and structural ordering at elevated temperatures. It is also necessary to take into account the catalytic effect of the carbide in contact, initially with liquid pitch and then with gradually condensed aromatic structures converted into fine crystalline turbostratic carbon and also to a better ordered phase corresponding to the graphitic phase. Processes related to the formation of carbon phases and their subsequent recrystallization occur with varying intensity. It has been confirmed in numerous publications that the catalytic effect of the $\mathrm{SiC}$ involves the formation of a graphite structure by dissolving disordered carbon phase and the precipitation of better ordered carbon at the $\mathrm{SiC} / \mathrm{C}$ interface [22]. Dissociation of the nanoparticles takes place at a different rate; smaller nanoparticles are more quickly degraded in polycrystalline carbon matrix. Such a mechanism reveals the Raman spectra and XRD analysis of CTP-based carbon samples.

The Raman spectra, ratio of $I_{\mathrm{D}} / I_{\mathrm{G}}$ intensities, $R$, and crystallinity of samples containing different amounts of $\mathrm{SiC}$ heated from 1000 to $2800^{\circ} \mathrm{C}$ are shown in Figures 2-5. The spectra of CTP-derived carbon residue obtained at $1000^{\circ} \mathrm{C}$ show two broad peaks at $1350 \mathrm{~cm}^{-1}$ and $1590 \mathrm{~cm}^{-1}$ 


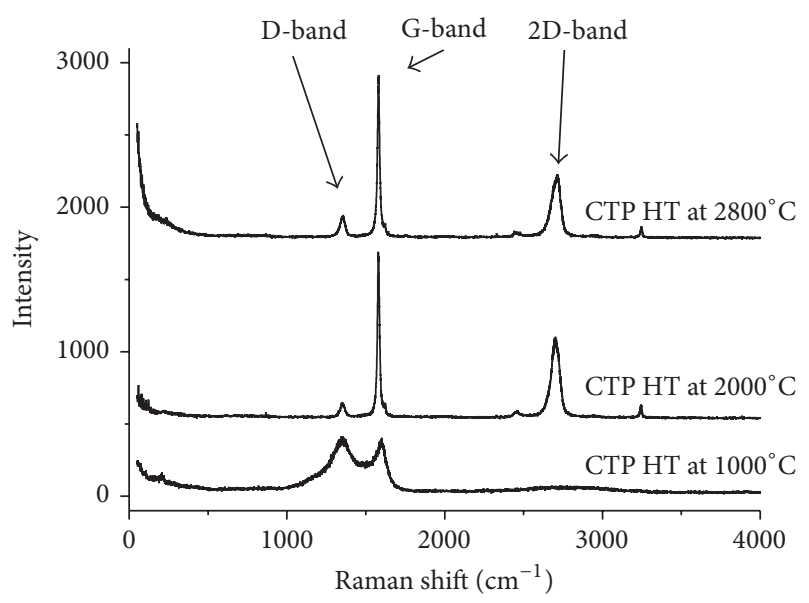

FIgURE 2: Raman spectra of pure CTP after heating to $1000^{\circ} \mathrm{C}$, $2000^{\circ} \mathrm{C}$, and $2800^{\circ} \mathrm{C}$.

(Figure 2). The peak at about $1350 \mathrm{~cm}^{-1}$, known as the Dband, corresponds to disordered carbon phase in carbon residue. The intensities of the D- and G-bands for the samples containing various amounts of $\mathrm{nSiC}$ annealed at various temperatures differ slightly; the respective $R$ changes $\left(I_{\mathrm{D}} / I_{\mathrm{G}}\right)$ for carbonized samples are also shown in the figure, together with the changes in the apparent crystallite thickness, $L_{a}$. This parameter was determined from the equation proposed by Cançado et al. [23]. The intensity ratios of carbon residue obtained at $1000^{\circ} \mathrm{C}$ are relatively high, indicating the presence of a large fraction of disordered carbon phase in the structure of the material (Figure 3). Carbon residues modified with $\mathrm{nSiC}$ after heating to $1000^{\circ} \mathrm{C}$ constitute a polycrystallite microstructure consisting of small size crystallites, $L_{a}$, and a higher $I_{\mathrm{D}} / I_{\mathrm{G}}$ ratio as compared to pure carbon samples. These relationships show the inhibiting effect of the presence of $\mathrm{nSiC}$ in carbon residue on the parameter $L_{a}$ and structural ordering of carbon residue.

After heating carbon samples with the ceramic nanofiller to $2000^{\circ} \mathrm{C}$, the crystallite sizes change and $I_{\mathrm{D}} / I_{\mathrm{G}}$ values differ significantly from those observed for the samples obtained at $1000^{\circ} \mathrm{C}$ (Figure 4 ). $I_{\mathrm{D}} / I_{\mathrm{G}}$ ratio for samples containing $10 \%$ ceramic nanofiller decreased from 0.666 for the CTP-based pure carbon to 0.351 , while the crystallite size $\left(L_{a}\right)$ increased from $28.6 \mathrm{~nm}$ for the pure carbon residue to $54.4 \mathrm{~nm}$ for the CTP with $10 \% \mathrm{nSiC}$. An nSiC content of $2 \%$ causes a significant decrease in $I_{\mathrm{D}} / I_{\mathrm{G}}$ ratio, indicating the presence of a higher fraction of the ordered graphitic phase in carbon samples. The Raman spectra of the samples obtained at $2000^{\circ} \mathrm{C}$ show second-order Raman peaks, known as the $2 \mathrm{D}$ bands, at about $2700 \mathrm{~cm}^{-1}$ (Figure 2). These peaks can be used to characterize the structure of carbon materials and their susceptibility to the graphitization [24].

For samples annealed at $2800^{\circ} \mathrm{C}$, variations in the $R$ parameter and crystallite sizes in function of $\mathrm{nSiC}$ are more complex (Figure 5). Nanoparticle grain fractions in the initial powder after deagglomeration and homogenization varied from 80 to $1050 \mathrm{~nm}$. It is probable that smaller ceramic nanoparticles dissolve above $2000^{\circ} \mathrm{C}$ more easily in carbon

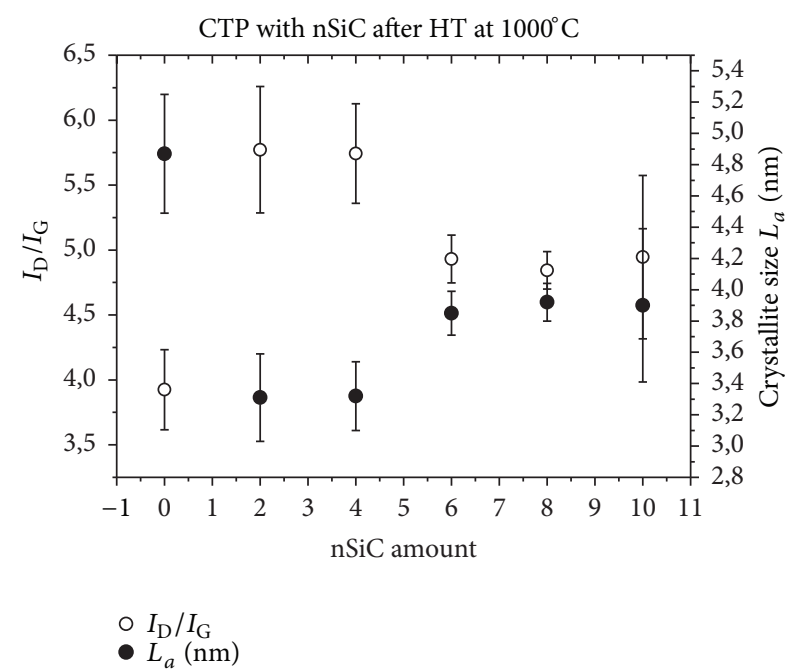

Figure 3: Raman spectra $I_{\mathrm{D}} / I_{\mathrm{G}}$ ratio and crystallite sizes $\left(L_{a}\right)$ of CTP-based carbon samples with different nSiC contents after heating to $1000^{\circ} \mathrm{C}$.

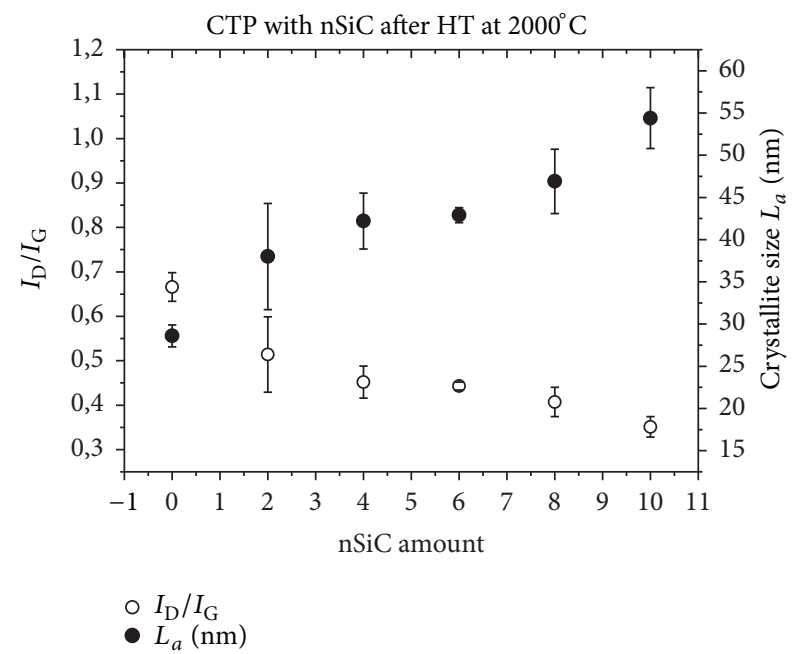

FIGURE 4: Raman spectra $I_{\mathrm{D}} / I_{\mathrm{G}}$ ratio and crystallite sizes $\left(L_{a}\right)$ of CTP-based carbon samples with different $\mathrm{nSiC}$ contents after heat treatment at $2000^{\circ} \mathrm{C}$.

matrix, resulting in the formation of small carbon crystallites until carbide dissolution occurs.

In this case, the correlation between the amount of carbide and $R$ and $L_{a}$ parameters seems to be randomized. The study indicates that, above $2000^{\circ} \mathrm{C}, \mathrm{SiC}$ reacts with the carbon matrix in a different way. Apart from the probable catalytic graphitization in the presence of carbide phase by dissolution of less ordered carbon phase followed by its precipitation into a better ordered carbon component, reactions of the decomposition of silicon carbide and silicon evaporation can take place. It is also expected that the observed structural changes in carbon phase depend upon the state of dispersion of carbide filler. Additional evidences for the proposed mechanism of interaction of $\mathrm{nSiC}$ nanoparticles with carbon 


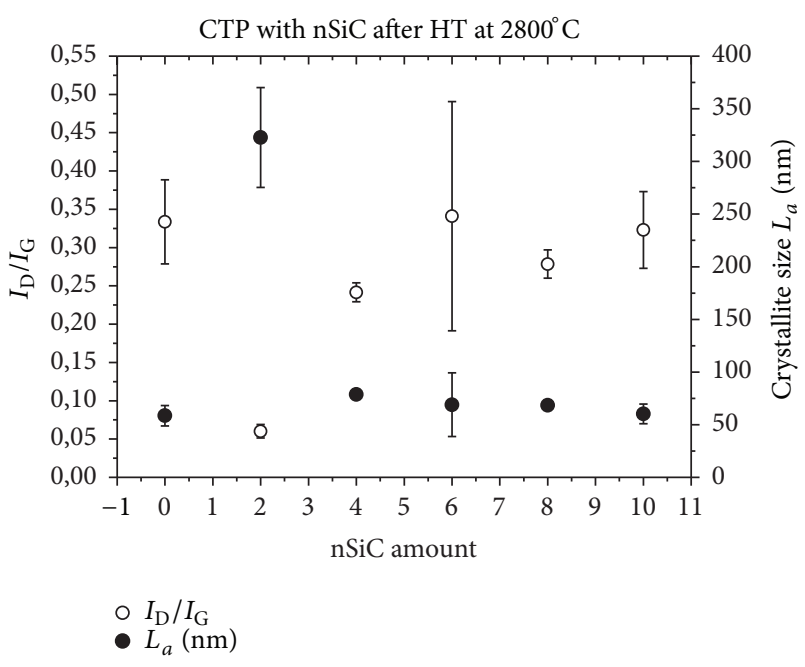

FIGURE 5: Raman spectra $I_{\mathrm{D}} / I_{\mathrm{G}}$ ratio and crystallite sizes $\left(L_{a}\right)$ of CTP-based carbon samples with different $\mathrm{nSiC}$ contents after heat treatment at $2800^{\circ} \mathrm{C}$.

matrix are provided by the XRD study. The diffractograms clearly show a reduction in the $\mathrm{SiC}$ content in samples heated above $2000^{\circ} \mathrm{C}$, and, in the case of samples heated at $2800^{\circ} \mathrm{C}$, the peak deriving from $\mathrm{SiC}$ disappears (Figure 6).

Phase analysis of carbon samples containing $10 \% \mathrm{nSiC}$ after heating to $2800^{\circ} \mathrm{C}$ (Figure 6) revealed that the samples either are composed of carbon phase with silicon carbide or contain only pure carbon fraction. Quantitative analysis of the samples modified with $\mathrm{nSiC}$ component revealed its decrease already after annealing at $2000^{\circ} \mathrm{C}$. The amount of the silicon carbide in carbon samples shown in Figure 7 was determined in relation to the initial amount of the CTP in samples before its annealing. Samples obtained at $2800^{\circ} \mathrm{C}$ do not contain any content of $\mathrm{nSiC}$. Carbon samples obtained at $1000^{\circ} \mathrm{C}$ display turbostratic structure consisting of two carbon phases (1 and 2) differing in structural parameters $d_{002}$ (Figure 8). Heating the samples to higher temperatures leads to an increase in the crystallinity of both phases and improvement of their structural ordering (a decrease in $d_{002}$ ).

The analysis was carried out for all samples based on deconvolution of the (002) peak into two carbon components, which enables acceptable function fitting. The second carbon phase (carbon phase 2), due to the higher $2 \theta$ values, represents the carbon component with a better structural ordering.

The image of these changes is complex, in particular when analyzing the impact of the amount of nanoparticles on the structure and microstructure of the carbon matrix.

The changes of the $c$-axis spacing $\left(d_{002}\right)$ and $L_{c}$ (apparent crystallite height) with amount of ceramic filler and temperature for both analyzed phases are shown in Tables 1 and 2. In accordance with our expectations, the higher the temperature, the smaller the value of $d_{002}$ for both carbon phases. Higher changes in $d_{002}$ parameter occur in the case of phase 2 .

Inconsistency has emerged between the results obtained from the two tests (Raman spectra, XRD) in the case of the samples heated to $2000^{\circ} \mathrm{C}$. The XRD analysis indicates an
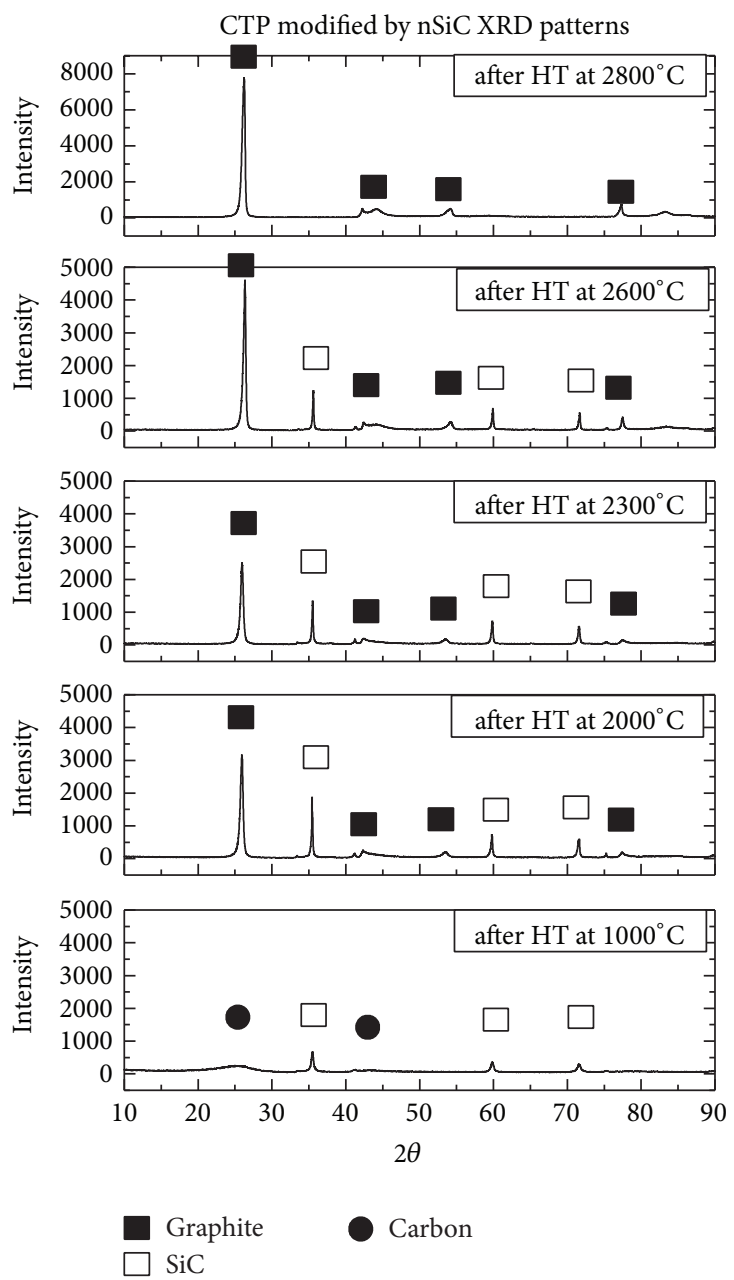

FIGURE 6: XRD patterns of CTP-based carbon residue with $10 \% \mathrm{nSiC}$ after annealing to different temperatures of 1000 to $2800^{\circ} \mathrm{C}$.

increase of the crystallites measured in the [002] direction up to $8 \mathrm{wt} \% \mathrm{SiC}$, and, for the maximum $\mathrm{SiC}$ content, $L_{c}$ is close to the value obtained for pure carbon residue. On the contrary, the Raman studies show monotonic growth of crystallites in the [011] direction $\left(L_{a}\right)$ with increasing $\mathrm{SiC}$ content.

This difference can be explained, on the one hand, by the different sizes of the analyzed areas of the samples determined by the two techniques. Raman study enables the analysis of sample size area of nanometric sizes, while the XRD measurements concern average sample areas of the order of several micrometres. Thus, a microstructural image of the measured feature by means of XRD seems to be closer to the real material, particularly when samples have a heterogeneous structure.

On the other hand, the Raman spectra make it possible to determine the apparent crystallite thicknesses $\left(L_{a}\right)$, while the XRD diffractograms allow the crystallite heights $\left(L_{c}\right)$ to be measured. It cannot be ruled out that the recrystallization of carbon residue in the presence of $\mathrm{nSiC}$ is an anisotropic process and changes in the size of crystallites in the " $a$ " direction are stronger than those in the " $c$ " direction. 
TABLE 1: Interplanar distance $\left(d_{002}\right)$ of carbon phases 1 and 2.

\begin{tabular}{lcccrr}
\hline nSiC amount & \multicolumn{3}{c}{ Carbon phase 1} & \multicolumn{2}{c}{ Carbon phase 2} \\
& $1000^{\circ} \mathrm{C}$ & $2000^{\circ} \mathrm{C}$ & $2800^{\circ} \mathrm{C}$ & $1000^{\circ} \mathrm{C}$ & $2000^{\circ} \mathrm{C}$ \\
\hline 0 & & \multicolumn{2}{c}{$d_{002}[\mathrm{~nm}]$} & 0,348 & 0,343 \\
2 & 0,397 & 0,346 & 0,340 & 0,350 & 0,344 \\
6 & 0,407 & 0,348 & 0,342 & 0,348 & 0,343 \\
10 & 0,393 & 0,347 & 0,343 & 0,349 & 0,339 \\
\hline
\end{tabular}

TABLE 2: Crystallite size $\left(L_{c}\right)$ of carbon phases 1 and 2.

\begin{tabular}{|c|c|c|c|c|c|c|}
\hline \multirow[b]{2}{*}{ nSiC amount } & \multicolumn{3}{|c|}{ Carbon phase 1} & \multicolumn{3}{|c|}{ Carbon phase 2} \\
\hline & $1000^{\circ} \mathrm{C}$ & $2000^{\circ} \mathrm{C}$ & $2800^{\circ} \mathrm{C}$ & $1000^{\circ} \mathrm{C}$ & $2000^{\circ} \mathrm{C}$ & $2800^{\circ} \mathrm{C}$ \\
\hline & \multicolumn{6}{|c|}{$L_{c}[\mathrm{~nm}]$} \\
\hline 0 & 1,3 & 16,1 & 19,4 & 2,0 & 22,0 & 43,0 \\
\hline 2 & 1,2 & 15,6 & 27,5 & 1,9 & 20,9 & 31,1 \\
\hline 6 & 1,2 & 17,0 & 22,7 & 2,0 & 25,1 & 29,4 \\
\hline 10 & 1,12 & 16,2 & 21,1 & 2,0 & 23,2 & 27,2 \\
\hline
\end{tabular}

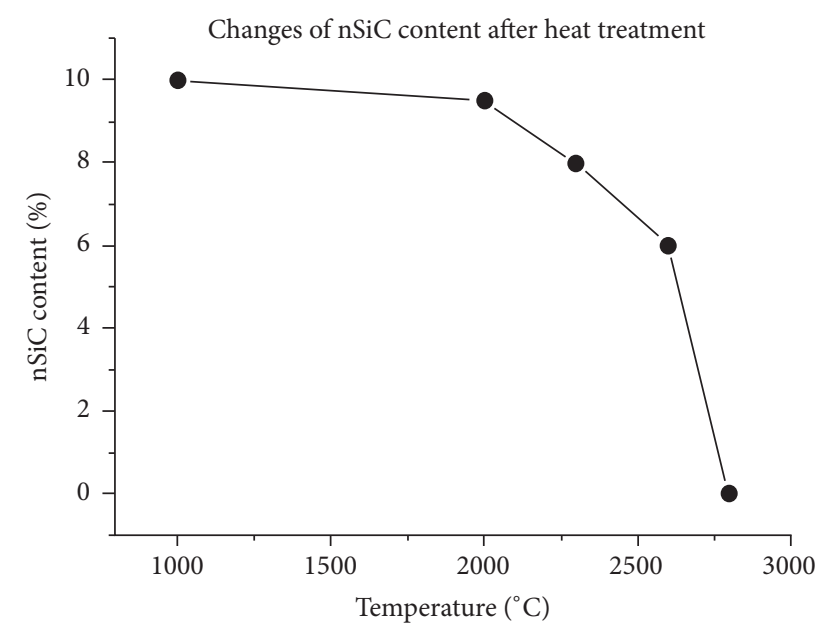

FIgURE 7: Variations of $\mathrm{nSiC}$ content in carbon samples after annealing at different temperatures.

The data collected in Tables 1 and 2, as well as in Figure 8, prove that carbon phase 2 obtained at $2000^{\circ} \mathrm{C}$ has a more crystalline structure compared to carbon phase 1 . The effect of $\mathrm{nSiC}$ on the microstructure of both carbon phases is evident. The crystallite sizes of carbon phase 2 increased from $22 \mathrm{~nm}$ in a pure carbon phase up to $28.1 \mathrm{~nm}$ in a sample containing $8 \% \mathrm{nSiC}$. On the contrary, the observed changes in $d$ spacings of the samples obtained at $2000^{\circ} \mathrm{C}$ are relatively weak. At higher temperature, that is, $2800^{\circ} \mathrm{C}$, the crystallite sizes $\left(L_{c}\right)$ and the $c$-axis spacing $\left(d_{002}\right)$ change in a complex way, probably because the temperature is too high, resulting in incongruent decomposition of $\mathrm{nSiC}$ and silicon evaporation [25].

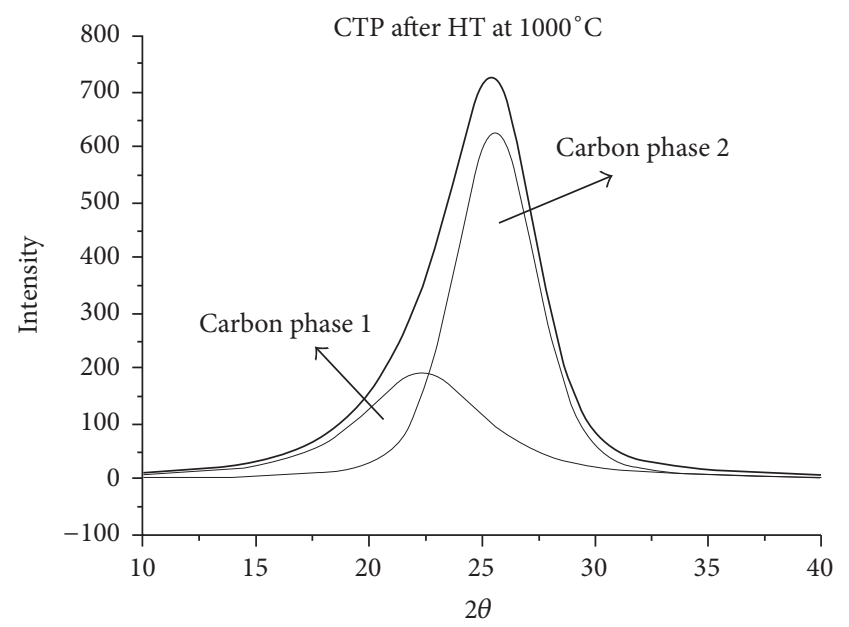

FIGURE 8: XRD of CTP-based samples; (002) peak deconvolution into two separate peaks.

\section{Conclusions}

Deagglomerated SiC nanopowder was mixed with liquid CTP and the suspension was heat-treated in the range from 1000 to $2800^{\circ} \mathrm{C}$. CTP-based carbon materials modified with $\mathrm{nSiC}$, depending on the ceramic content and final temperature, differ in their structure and microstructure. Due to the presence of $\mathrm{nSiC}$ during carbonization of CTP to $1000^{\circ} \mathrm{C}$, the carbon crystallite growth is inhibited. Above $2000^{\circ} \mathrm{C}$, the presence of $\mathrm{nSiC}$ promotes the growth of crystallites, but the microstructure of carbon samples becomes more heterogeneous in comparison to carbon samples without ceramic nanofiller. 


\section{Conflicts of Interest}

The authors declare that they have no conflicts of interest.

\section{Acknowledgments}

This study was funded by the Polish National Centre for Research and Development, Project no. PBS2/B5/27/2013 19.19.160.86540.

\section{References}

[1] S. Ragan and H. Marsh, "Science and technology of graphite manufacture," Journal of Materials Science, vol. 18, no. 11, pp. 3161-3176, 1983.

[2] M. Inagaki and F. Kang, Materials Science and Engineering of Carbon: Fundamentals (Second Edition), ButterworthHeinemann, Oxford, UK, 2014.

[3] M. Inagaki and F. Kang, Materials Science and Engineering of Carbon: Fundamentals, Butterworth-Heinemann, 2nd edition, 2014.

[4] Z. Fan, Y. Song, J. Li et al., "Oxidation behavior of fine-grained SiC-B4C/C composites up to $1400^{\circ} \mathrm{C}$," Carbon, vol. 41, no. 3, pp. 429-436, 2003.

[5] M.-S. Kim, K. Y. Rhee, and S.-J. Park, "Pitch coating of SiC and its effects on the thermal stability and oxidation resistance of SiC/epoxy composites," Composites Part B: Engineering, vol. 94, pp. 218-223, 2016.

[6] O. S. Efimova, G. P. Khokhlova, and Y. F. Patrakov, "Properties of silicon-containing carbon materials prepared using coal-tar pitch," Solid Fuel Chemistry, vol. 44, no. 2, pp. 112-117, 2010.

[7] K. Kawamura, M. Ono, and K. Okazaki, "Silicon carbide/carbon composite sheets derived from PCS/coal-tar pitch mixtures," Carbon, vol. 30, no. 3, pp. 429-434, 1992.

[8] C. Czosnek, J. Wolszczak, M. Drygaś, M. Góra, and J. F. Janik, "Nano-SiC implantation into the structure of carbon/graphite materials made by pyrolysis (carbonization) of the precursor system coal tar pitch/poly(dimethylsiloxane)," Journal of Physics and Chemistry of Solids, vol. 65, no. 2-3, pp. 647-653, 2004.

[9] T. L. Dhami, O. P. Bahl, and B. R. Awasthy, "Oxidation-resistant carbon-carbon composites up to $1700^{\circ} \mathrm{C}$," Carbon, vol. 33, no. 4, pp. 479-490, 1995.

[10] L. M. Manocha, S. Manocha, K. B. Patel, and P. Glogar, "Oxidation behaviour of Carbon/Carbon Composites impregnated with silica and silicon oxycarbide," Carbon, vol. 38, no. 10, pp. 1481-1491, 2000.

[11] C. C. Chou and Y. C. Ko, "Formation and structure of SiC whiskers from metallic silicon and coal tar pitch in refractories during sintering," Journal of Materials Science Letters, vol. 5, no. 2, pp. 209-213, 1986.

[12] S. Safi and R. Yazdani Rad, "In situ synthesis of nano size silicon carbide and fabrication of $\mathrm{CSiC}$ composites during the siliconization process of mesocarbon microbeads preforms," Ceramics International, vol. 38, no. 6, pp. 5081-5087, 2012.

[13] K. Suresh, K. Sweety, K. Anil, S. Anupam, A. K. Gupta, and G. Rohini Devi, "Mechanical properties of LSI based 3Dstitched-C-SiC composites prepared by coal-tar pitch as carbon precursor," Scripta Materialia, vol. 58, no. 10, pp. 826-829, 2008.

[14] V. Raman, G. Bhatia, A. K. Mishra, S. Bhardwaj, and K. N. Sood, "Synthesis of silicon carbide nanofibers from pitch blended with sol-gel derived silica," Materials Letters, vol. 60, no. 29-30, pp. 3906-3911, 2006.

[15] H. Zhu, X. Li, F. Han et al., "The effect of pitch-based carbon fiber microstructure and composition on the formation and growth of $\mathrm{SiC}$ whiskers via reaction of such fibers with silicon sources," Carbon, vol. 99, pp. 174-185, 2016.

[16] D. Mikociak, A. Magiera, G. Labojko, and S. Blazewicz, "Effect of nanosilicon carbide on the carbonisation process of coal tar pitch," Journal of Analytical and Applied Pyrolysis, vol. 107, pp. 191-196, 2014.

[17] Z. Liu, Q. Guo, J. Shi, G. Zhai, and L. Liu, "Preparation of doped graphite with high thermal conductivity by a liquid mixing process," Carbon, vol. 45, no. 9, pp. 1914-1916, 2007.

[18] H. Qiu, L. Han, and L. Liu, "Properties and microstructure of graphitised $\mathrm{ZrC} / \mathrm{C}$ or SiC/C composites," Carbon, vol. 43, no. 5, pp. 1021-1025, 2005.

[19] C. Czosnek, W. Ratuszek, J. F. Janik, and Z. Olejniczak, "XRD and 29Si MAS NMR spectroscopic studies of carbon materials obtained from pyrolyses of a coal tar pitch modified with various silicon-bearing additives," Fuel Processing Technology, vol. 79, no. 3, pp. 199-206, 2002.

[20] O. S. Efimova, G. P. Khokhlova, and Y. F. Patrakov, “Thermal conversion of coal-tar pitch in the presence of silicon compounds," Solid Fuel Chemistry, vol. 44, no. 1, pp. 5-11, 2010.

[21] M. Gubernat, J. Tomala, W. Frohs, A. Fraczek-Szczypta, and S. Blazewicz, "De-agglomeration and homogenisation of nanoparticles in coal tar pitch-based carbon materials," Journal of Nanoparticle Research, vol. 18, article 56, 2016.

[22] B. Kelly, Book Review: Physics of Graphite, Applied Science Publishers, 1981.

[23] L. G. Cançado, K. Takai, T. Enoki et al., "General equation for the determination of the crystallite size $L_{a}$ of nanographite by Raman spectroscopy," Applied Physics Letters, vol. 88, no. 16, Article ID 163106, 2006.

[24] A. C. Ferrari, "Raman spectroscopy of graphene and graphite: disorder, electron-phonon coupling, doping and nonadiabatic effects," Solid State Communications, vol. 143, no. 1-2, pp. 47-57, 2007.

[25] T. Y. Kosolapova, "Silicon carbide," in Carbides, pp. 191-199, Springer US, 1971. 

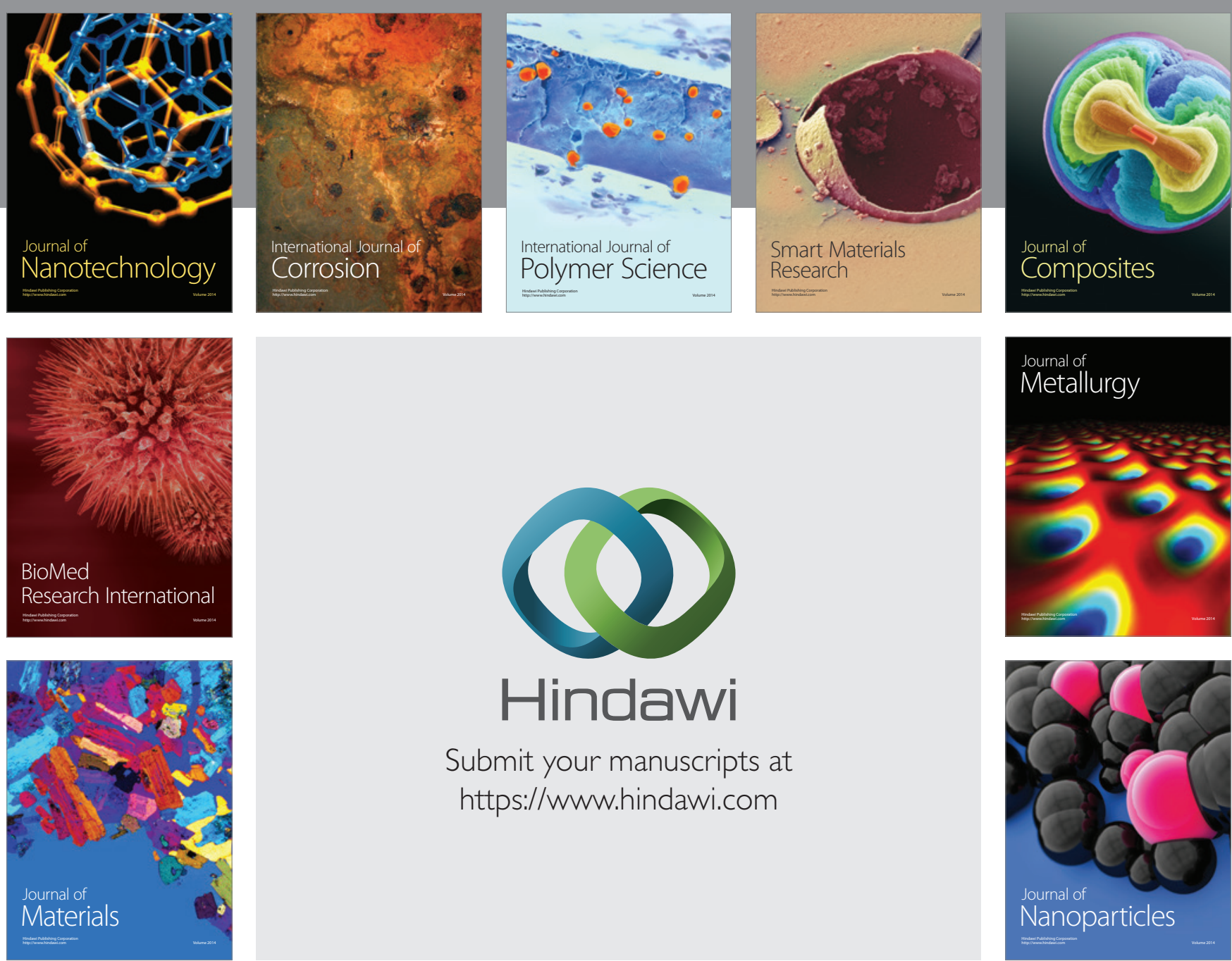

\section{Hindawi}

Submit your manuscripts at

https://www.hindawi.com

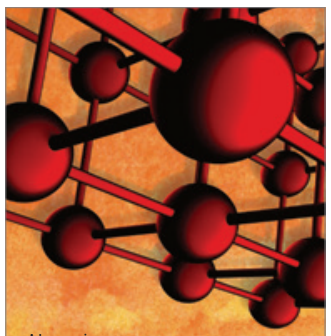

Materials Science and Engineering
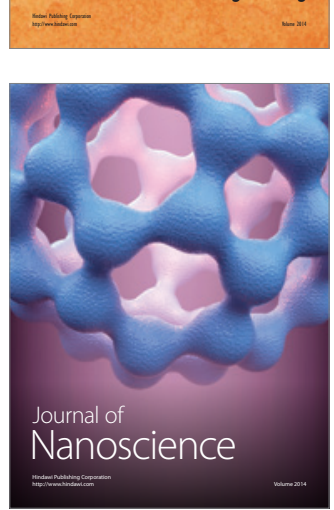
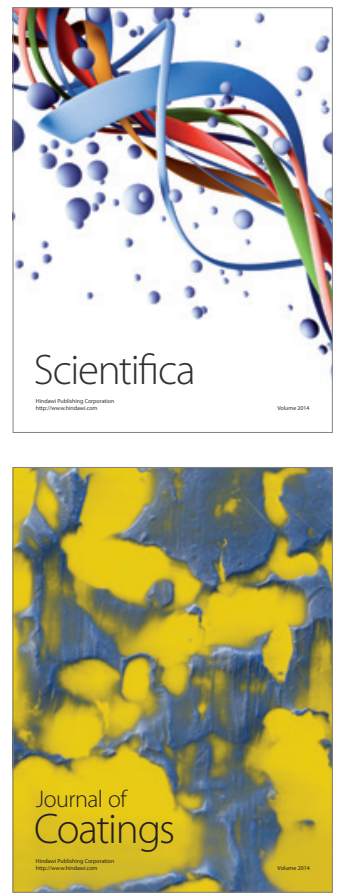
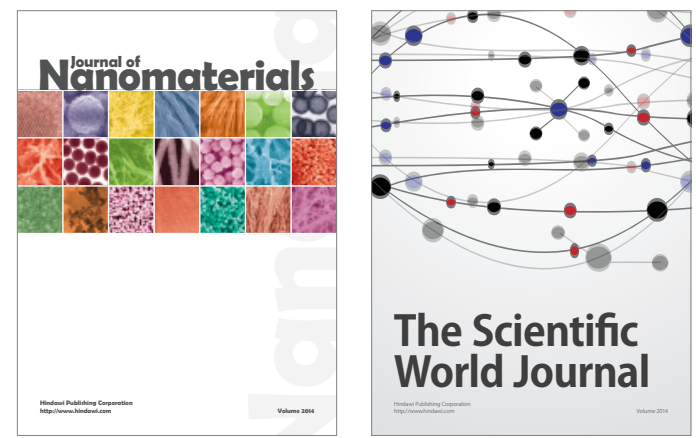

The Scientific World Journal
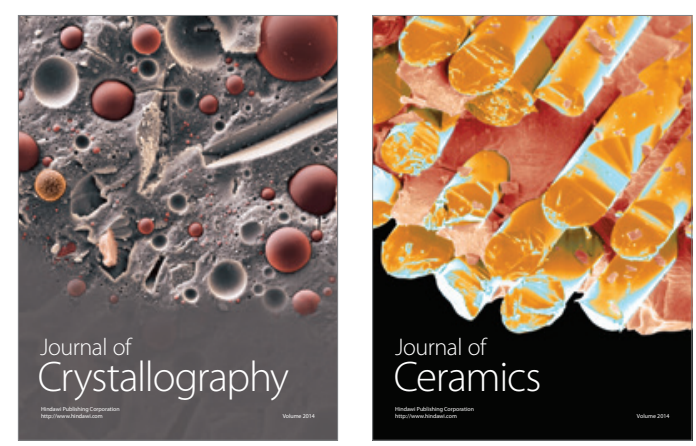
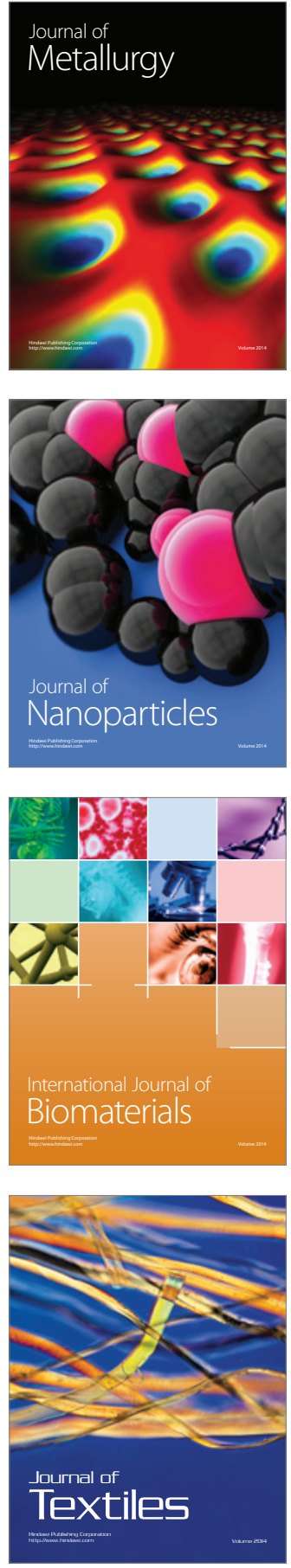